\title{
Implante dentário com carga imediata na região anterior superior: relato de caso clínico
}

\author{
Dental implant with immediate load in the upper anterior region: \\ clinical case report
}

Catiélys Níobe Matiello* Micheline Sandini Trentin ${ }^{* *}$

\section{Resumo}

Objetivo: o objetivo desta pesquisa de caso clínico é relatar de forma sucinta, os possíveis fatores que possam influenciar na osseointegração de implantes com carga imediata e descrever os métodos que levam ao seu sucesso clínico. Relato de caso: paciente do gênero feminino, 19 anos de idade, bom estado geral de saúde, procurou atendimento em clínica particular queixando-se de escurecimento e mobilidade no dente 21, devido ao trauma sofrido na região, em 2007. Em 2012, foi planejada a exodontia desse elemento, em decorrência de fratura dental e mobilidade acentuada. Na mesma sessão, foi realizada a instalação de implante dentário com carga imediata, buscando com esses procedimentos a manutenção da saúde e estética dos tecidos periodontais, além da função mastigatória e conforto da paciente. Considerações finais: os resultados clínicos foram favoráveis e condizentes com a técnica utilizada. A altura óssea e gengival foi preservada, resultando em estética favorável da prótese fixa definitiva. Dessa forma, pode-se considerar que o planejamento interdisciplinar foi essencial para a obtenção desse resultado.

Palavras-chave: Implante dentário. Osseointegração. Cirurgia Bucal.

\section{Introdução}

A reabilitação oral com implantes osseointegrados destaca-se como um método atual e eficaz em pacientes edêntulos totais ou parciais. A osseointegração entre implante e tecido ósseo receptor deve ocorrer adequadamente, sendo a integração óssea a chave do sucesso cirúrgico. Contudo, muitos são os fatores a serem considerados para que o procedimento ocorra de maneira satisfatória.

Uma análise cuidadosa do local pré-operatório e das técnicas cirúrgicas, incluindo vários métodos para o planejamento cirúrgico-protético, são pré-requisitos para uma ótima localização do implante e a restauração estética subsequente. É aconselhável que uma equipe integrada envolva cirurgião-dentista, periodontista, implantodontista e protesista ou um profissional que possua essas características para que assim possam ser obtidos resultados estéticos agradáveis ${ }^{1}$.

O profissional da odontologia deve estar atualizado em relação às técnicas cirúrgicas e propostas de tratamento reabilitador, além de capacitado adequadamente a executá-las, para alcançar o sucesso do tratamento. O profissional deve expor ao pacien-

Acadêmica, Faculdade de Odontologia, Universidade de Passo Fundo, Passo Fundo, Rio Grande do Sul, Brasil

Doutora em Periodontia, Universidade Estadual Paulista Júlio de Mesquita Filho, Saõ Paulo, professora de Clínica Integrada, Periodontia e Implantodontia, Faculdade de Odontologia, Universidade de Passo Fundo, Passo Fundo, Rio Grande do Sul, Brasil 
te as diversas opções de tratamento para o caso e estar atento à queixa principal e expectativa deste acerca do resultado do tratamento ${ }^{2}$.

A osseointegração depende de quatro fatores principais: biocompatibilidade dos implantes, alto nível de precisão entre o implante e o sítio ósseo receptor, técnicas cirúrgicas que minimizem o trauma aos tecidos injuriados e condições das cargas pós-operatórias. Os critérios fundamentais das características da dentição natural da região anterior da maxila incluem uma boa saúde gengival, assim como forma e composição estrutural específica, cor, opalescência, translucidez, transparência e textura superficial dos incisivos e caninos. Ainda, em casos de perda múltipla de dentes anteriores, ocorre também significativa deficiência de tecido mole e duro ${ }^{3}$.

O sucesso da instalação imediata de um implante envolve também a avaliação do prognóstico dos tecidos moles adjacentes, no qual o resultado estético dependerá também da extração atraumática e ausência de danos ao tecido ósseo ${ }^{2,4}$.

Por essa razão, faz-se necessária uma abordagem multidisciplinar na maioria dos casos, já que toda a responsabilidade da decisão sobre manter ou extrair dentes considerados comprometidos recai sobre o cirurgião-dentista ${ }^{4}$. Em relação a dentes com prognóstico duvidoso, a realização do tratamento endodôntico não é garantia de manutenção do dente. Fraturas radiculares, recidivas de cárie e lesão apical se relacionam aos insucessos e perdas dentais, já as perdas de estrutura dental estão diretamente ligadas à fratura do dente. Além disso, canais radiculares com limitações anatômicas e persistência de bactérias levam ao insucesso e à necessidade de um retratamento endodôntico ${ }^{5}$.

Em regiões sem deficiências teciduais significativas, a técnica de incisão palatina para implantes anteriores de maxila está sendo aplicada com sucesso, com o objetivo de preservar tecido gengival queratinizado na face vestibular da futura prótese sobre implante ${ }^{4}$. Outro parâmetro crucial é a manutenção de, no mínimo, $1 \mathrm{~mm}$ de lâmina óssea na região vestibular do implante, minimizando o risco de retrações de tecido mole peri-implante, fator fundamental para a estética. Além disso, o desenho da supraestrutura na região interproximal é outro aspecto importante quando se trata de considerações estéticas relacionadas à prótese sobre implantes na região dos dentes anterossuperiores. Para promover condições ideais ao tecido mole relacionado, uma linha de contato interdental longa é estabelecida, localizada ligeiramente à região palatina de restauração. Esse desenho oferece um suporte melhor para o tecido mole interproximal e reduz a possibilidade de ocorrer o chamado "triângulo negro"6.

O objetivo deste relato de caso clínico é descrever a técnica da instalação de implantes na região anterior de maxila, em situações que pode ser utilizada carga imediata, relatando as indicações, contraindicações, vantagens e desvantagens da referida técnica.

\section{Relato de caso}

O sujeito do caso relatado neste trabalho é uma paciente do gênero feminino, de 19 anos de idade, com bom estado geral de saúde, que procurou atendimento em clínica particular queixando-se de escurecimento no elemento dental 21 (Figura 1a). Após anamnese, exames clínicos intra e extraoral e imaginológicos detalhados, foram realizadas radiografias periapicais (Figura 1b), pois havia suspeita de fratura vertical na região corono-radicular do referido dente; suspeita confirmada pela realização de radiografia tipo Cone-beam. O motivo do escurecimento dentário foi decorrente de um trauma coronário da paciente aos 13 anos de idade, favorecendo fratura radicular vertical posterior, enfraquecimento do elemento dentário e mobilidade acentuada no elemento dentário.
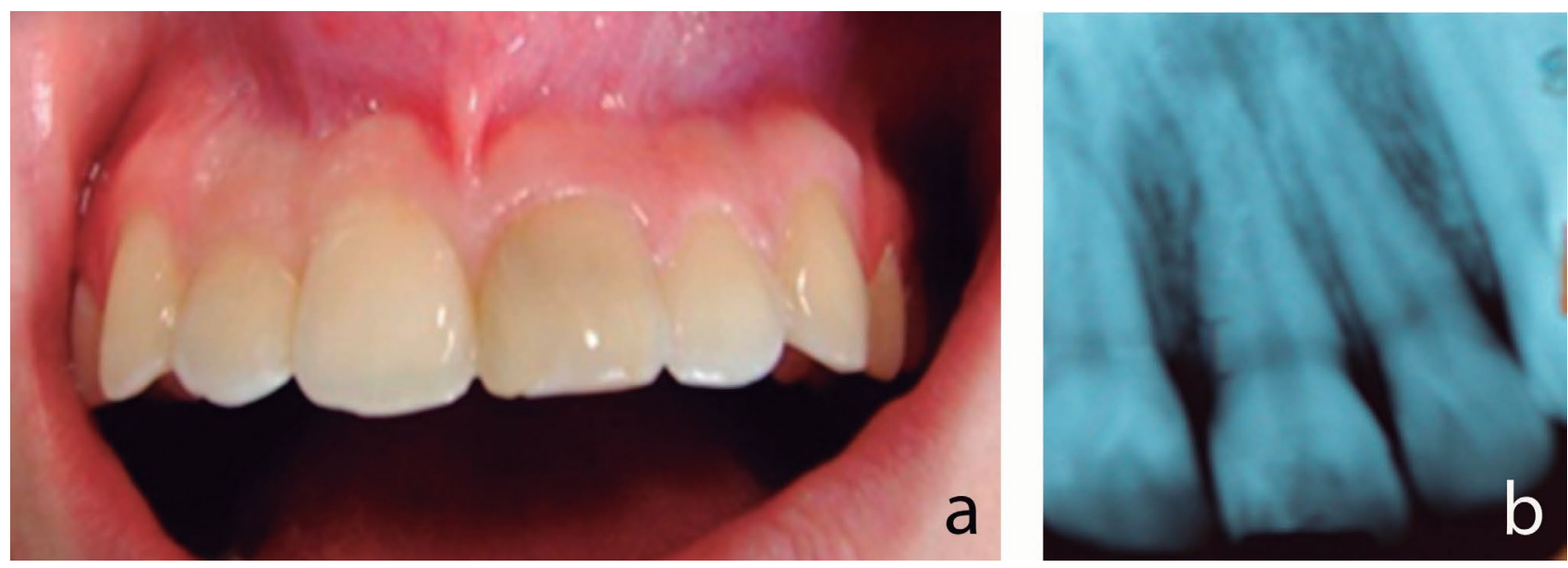

Figura 1 - a) Aspecto inicial do elemento dentário 21; b) radiografia periapical 
De acordo com o planejamento do caso clínico, o enceramento diagnóstico foi confeccionado e resultou em uma possibilidade cirúrgica viável e favorável. A exodontia do elemento dentário 21, que apresentava mobilidade grau III, foi realizada sete anos após o trauma inicial (Figura 2) . Também, na mesma sessão, foi realizada a instalação de implante osseointegrável na região e a adaptação imediata de coroa provisória - carga imediata (Figura 3), buscando a manutenção da saúde e estética dos tecidos periodontais, além da função mastigatória e conforto psicossocial da paciente.
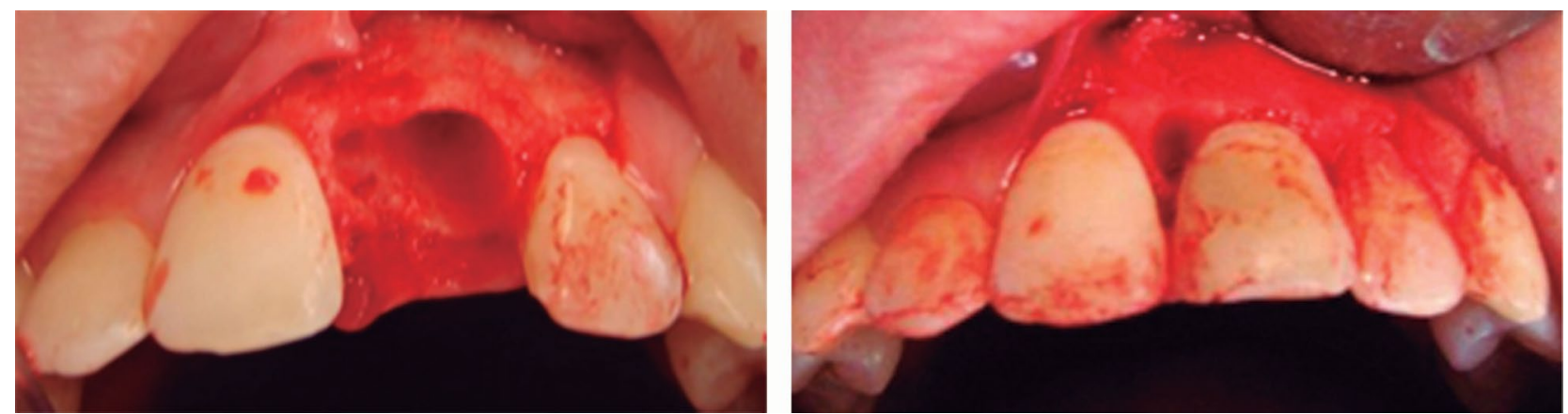

Figura 2 - Deslocamento do tecido gengival e alvéolo do elemento dentário

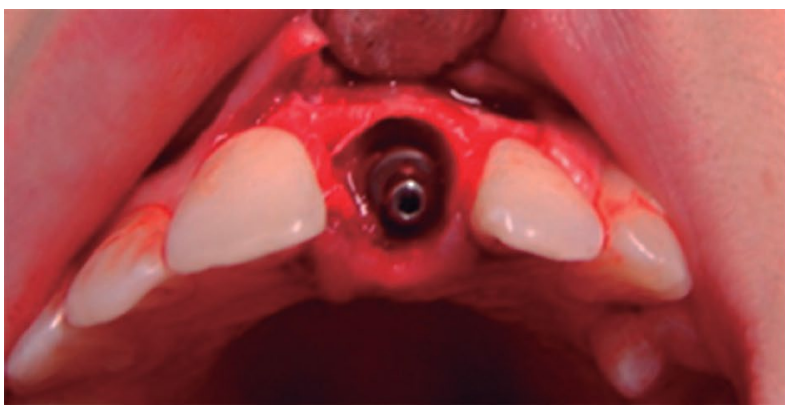

Figura 3 - Implante instalado no alvéolo e sutura final

Um enxerto ósseo liofilizado na área da exodontia foi necessário devido à amplitude do alvéolo, sendo instalado implante do tipo Cone Morse com torque de 50 Newtons (Alvim $5.0 \mathrm{~mm}$ x $13.0 \mathrm{~mm}$ ) Neodent ${ }^{\circledR}$, e após a instalação de munhão universal $3.3 \mathrm{~mm} \times 6 \times 08 \mathrm{~mm}$.

Ao final, a prótese provisória foi adaptada e ajustada em boca, corrigindo as limitações e conferindo os movimentos bordejantes e intrabordejantes, ou seja, com a correta confecção e adaptação da coroa provisória. Dessa forma, foi possível a manutenção da integridade marginal do periodonto, principalmente das papilas interdentais, favorecendo também a correta forma da gengiva no limite coroa-implante.

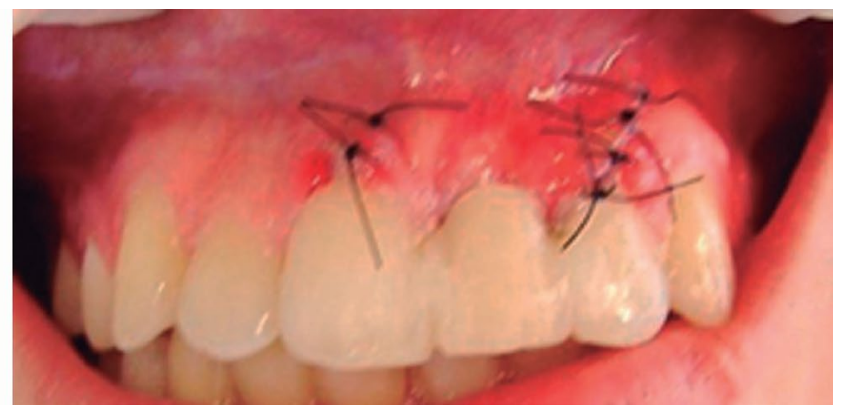

Após dez dias, as suturas foram removidas, os ajustes oclusais e a adaptação marginal foram verificados. $\mathrm{O}$ acompanhamento clínico da prótese provisória, com consultas e avaliações de higiene bucal do paciente, foi realizado por sete meses, tempo necessário para a obtenção da osseointegração.

A fratura radicular do dente 21 ocorreu na base cervical do alvéolo, favorecendo, dessa forma, o prognóstico da cirurgia e a estabilidade dos tecidos ósseos e gengivais. Após o período de cicatrização, foi realizada a confecção de coroa metalocerâmica cimentada (Figura 4). O caso continua sendo acompanhado após a instalação da coroa definitiva, tendo como resultado a satisfação funcional e estética da paciente.
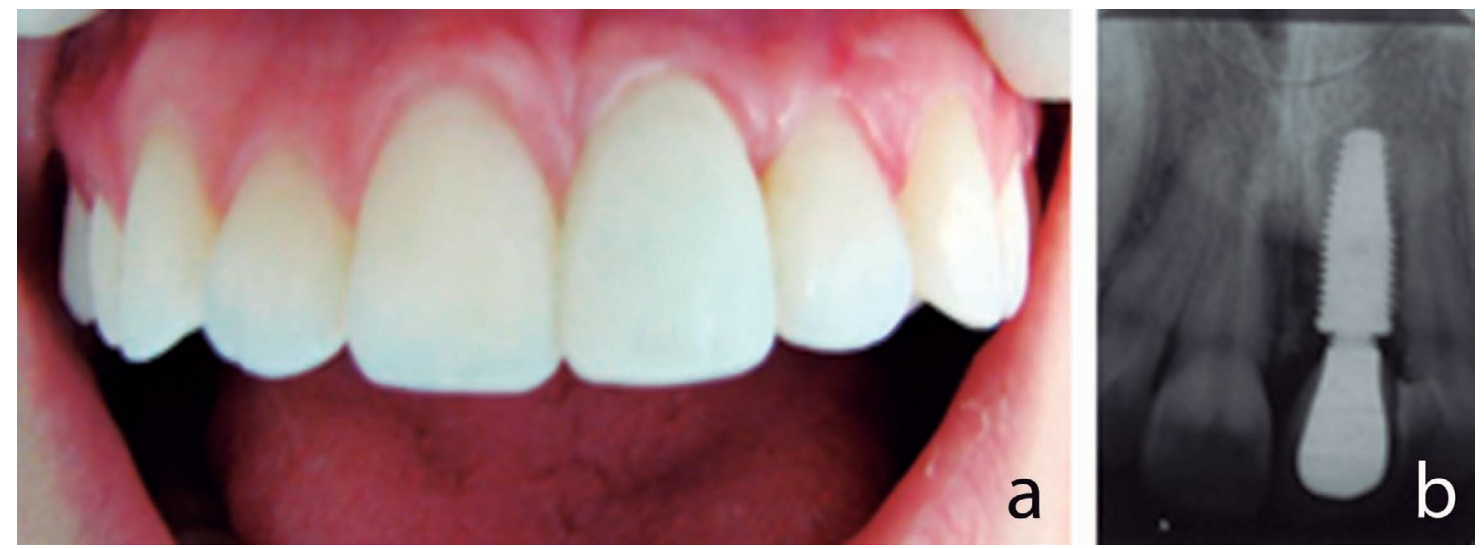

Figura 4 - a) Sete meses após a cimentação da coroa metalocerâmica definitiva; b) radiografia periapical do dente 21 


\section{Discussão}

O tratamento com implantes unitários imediatamente após a extração de dentes condenados provou ser uma modalidade com sucesso previsível. Para tanto, deve-se levar em consideração fatores clínicos e de planejamento reverso para um correto diagnóstico e plano de tratamento integrado. Uma das principais vantagens dos implantes imediatos é a manutenção da forma original dos tecidos moles, principalmente das papilas interproximais, e a preservação da arquitetura óssea e gengival peri-implantar de maneira previsível, reduzindo a reabsorção óssea alveolar e aprimorando o resultado estético $^{7,8}$.

A instalação de implantes unitários no momento da extração dentária passou a ser uma alternativa significativa para o paciente, pois, além de satisfazê-lo em relação à estética, a carga imediata possibilita uma visualização do resultado final do tratamento reabilitador ${ }^{8-10}$.

A carga imediata sobre implantes apresenta vantagens estéticas e funcionais em comparação à técnica convencional. A colocação de prótese fixa imediatamente após o ato cirúrgico resulta em diminuição do número de consultas, contribui para a manutenção da arquitetura dos tecidos ósseos e gengivais, eliminando o segundo estágio cirúrgico, reduz o tempo e o custo do tratamento, bem como minimiza o inadequado posicionamento da prótese nos procedimentos de fase única ${ }^{11-14}$.

Indices de sucesso dos implantes e resultados clínicos associados à instalação imediata ou não foram observados ${ }^{15}$. A hipótese de Chaushu et al. ${ }^{16}$ (2001), em estudo clínico, foi de que a carga imediata de restaurações implantossuportadas, substituindo dentes perdidos individuais, poderia ser um procedimento bem-sucedido.

Em uma avaliação clínica dos métodos atualmente disponíveis para restauração estética anterior da maxila, utilizando implantes unitários imediatamente carregados, Tsirlis ${ }^{17}$ (2005) avaliou 43 pacientes com implantes unitários e carga não-funcional imediata, divididos em grupo A e B (instalação imediata do implante e instalação tardia, respectivamente). Os procedimentos terapêuticos foram considerados bem-sucedidos em todos os casos, sem perda marginal radiográfica peri-implante significativa. Em resumo, a utilização de implantes dentários com carregamento não funcional em áreas particularmente estéticas é recomendada sem reservas, em virtude da existência dos requisitos anatômicos, boa estabilidade inicial e ausência de perda óssea na área receptora do implante. Além disso, a aplicação desse método de tratamento conduz a um resultado estético particularmente exitoso e reduz o número de cirurgias e a duração do tratamento.
Também em um estudo clínico prospectivo, Calvo et al. ${ }^{18}$ (2000) avaliaram a taxa de sucesso dos implantes, resposta dos tecidos peri-implantares e resultados estéticos de 35 implantes imediatos com restaurações unitárias provisórias imediatas. Aos doze meses de acompanhamento pós-operatório, todos os implantes encontravam-se osseointegrados, e os pacientes satisfeitos em relação aos resultados estéticos. O mesmo resultado com a satisfação do paciente também foi no caso clínico relatado neste trabalho.

Em estudo prospectivo, Becker et al. ${ }^{19}(2005)$ apresentaram os resultados de 92 implantes imediatos instalados em regiões de incisivos superiores, com colocação simultânea de coroas provisórias implantossuportadas. Depois de dois anos de acompanhamento, seis implantes foram perdidos, e 86 apresentaram-se sem sinais de mobilidade, inflamação peri-implantar ou reações adversas.

Em 2004, um dos grupos de estudos do Third ITI Consensus Conference apresentou uma declaração de consenso quanto à colocação de implantes em alvéolos frescos pós-extração. Segundo ele, há diversos estudos mencionando que a taxa de sobrevivência de implantes imediatos é semelhante à de implantes colocados em rebordos cicatrizados. Frequentemente, quando implantes são imediatamente instalados após a extração, ocorre um espaço entre as paredes circundantes do alvéolo e a superfície do implante, resultando em retardo e/ou deficiência do processo de osseointegração ${ }^{20}$. Para o preenchimento desse espaço, foi utilizado o enxerto de osso liofilizado como substituto ósseo.

Por fim, vários autores mencionam excelentes resultados clínicos com esse tipo de abordagem, e, consequentemente, a aceitação pelos pacientes tem aumentado. Não obstante, a simples previsibilidade na obtenção da osseointegração não é garantia de sucesso clínico em implantodontia, principalmente tratando-se de sítios implantares em área estética ${ }^{21,22}$.

\section{Considerações finais}

O implante com carga imediata é um procedimento rápido, eficaz e seguro para a solução de casos em que o elemento dental foi indicado para a exodontia. Contudo, para alcançar um resultado satisfatório, é importante seguir um rigoroso protocolo e planejamento que inclui: qualidade e quantidade óssea, relação de dentes antagonistas, técnica atraumática para a exodontia e escolha do implante.

O objetivo da carga imediata é restabelecer saúde e condições propícias para restaurações adequadas, que permitam boa integração com os tecidos peri-implantares, assim como adequado controle de biofilme bacteriano. 


\section{Abstract}

Introduction: This clinical case aims to briefly report the factors that may potentially influence osseointegration of immediate implants with immediate load, and to describe the methods that lead to the same clinical success. Case report: Female patient, 19 years old, good general health, sought treatment at a private care clinic complaining of darkening and mobility of tooth 21, due to trauma in that area in 2007. In 2012, the extraction of this element was planned because of dental fracture and severe mobility. In the same session, a dental implant with immediate load was installed; this procedure aimed to maintain the health and the esthetics of periodontal tissues, as well as the masticatory function and patient comfort. Final Considerations: Clinical outcomes were favorable and consistent with the technique used. Bone and gingival heights were preserved, resulting in favorable esthetics of the final fixed prosthesis. Thus, it may be considered that interdisciplinary planning was the key factor to obtain the present result.

Keywords: Immediate dental implant. Osseointegration. Immediate load.

\section{Referências}

1. Bornstein MM, Cionca N, Mombelli A. Systemic conditions and treatments as risks for implant therapy. Int $\mathrm{J}$ Oral Maxillo Fac Implants 2009; 24 suppl:12-27.

2. Salama H, Rose LF, Salama M, Betts NJ. Immediate loading of bilaterally slpinted titanium root form implants in fixed prosthodontics technique reexamined: two case reports. Practical Periodontics 1995; 15(4):344-61.

3. Buser D, Von Arx T. Surgical procedures in partially edentulous patients with ITI implants. Clin Oral Implants Res 2000; 11:83-100

4. Bersani E,Coppedê AR, De Paula Pinto Prata HH, Miglioranca RM, De Mayo TM. Carga em implantes instalados em alvéolos frescos após extração de dentes posteriores sem procedimento de enxertos e sem retalhos. Rev Implant News 2010; 7(3a-PBA):73-81.

5. Trentin MS, Linden MSS, Girardi G, Shibli JA. Implantodontia Clínica baseada em evidência científica. In: Shibli J. Parâmetros Clínicos para a Manutenção de dentes com prognóstico duvidoso. São Paulo: Quintessence; 2012. p. 133-40.

6. Jassé FF, Segalla JCM, Silva MAB, Porto RO, Calistrato RS, Saad JRC. Carga Imediata em Implantes Unitários: Revisão da Literatura. Unopar Cient Cien Biol Saude [periódico on-line] 2014 [citado 2010 out. 23]; 12(1)35-8[telas]. Disponível em URL: http://revistas.unopar.br/index.php/ biologicas/article/view/.

7. Lindeboom JA, Frenken JW, Dubois L. Immediate loading versus immediate provisionalization of maxillary single-tooth replacements: a prospective randomized study with biocomp implants. J Oral Maxillofac Surg 2006; 64(6):936-42.

8. Ericsson I, Nilson H, Lindh T, Nilner K, Randow K. Immediate functional loading of Branemark single tooth implants. An 18-month clinical pilot follow-up study. Clin Oral Implants Res 2001; 11(1):26-33.

9. Glauser R, Sennerby L, Meredith N. Resonance frequency analysis of implants subjected to immediate or early functional occlusal loading. Successful vs. failing implants. Clin Oral Implants Res 2004; 15(4):428-34.
10. Atieh MA, Payne AG, Duncan WJ, Silva RK, Cullinan MP. Immediate placement or immediate restoration/loading of single implants for molar tooth replacement: a systematic review and meta-analysis. Int J Oral Maxillofac Implants 2010; 25:401-15.

11. Nkenke E, Fenner M. Indications for immediate loading of implants and implant success. Clin Oral Implants Res 2006; 17(2):19-34.

12. Wagenberg BD, Ginsburg TR. Immediate implant placement on removal of the natural tooth: retrospective analysis of 1,081 implants. Compend Contin Educ Dent 2001; $22: 399-408$.

13. Attard NJ, Zarb GA. Immediate and early implant loading protocols: a literature review of clinical studies. J Prosthet Dent 2005; 94:242-58.

14. Wohrle P, Rubenstein JE, Silva JD, Wang NH. Ten-year results of Branemark implants immediately loaded with fixed prostheses at implant placement. J Oral Maxillofac Implants [periódico on-line] 1997. [citado $2014 \mathrm{dez} 8$ 8; Disponível em url: http://ncbi.nlm.nih.gov/pubmed/9274078

15. Chen ST, Wilson Jr TG, Hammerle CHF. Immediate or early placement of implants following tooth extraction: Review of biologic basic, clinical procedures and outcomes. Int J Oral Maxillofac Implants 2004; 19(suppl):12-25.

16. Chaushu G, Chaushu S, Tzahar A, Dayan D. Immediate loading of single tooth implants: immediate $\mathrm{x}$ non immediate implantation: a clinical report. JOMI 2001; 16(2):267-72.

17. Tsirlis AT. Clinical evaluation of immediate loaded upper anterior single implants. Implant Dent 2005; 14(1):94-103.

18. Calvo RMP, Müller E, Garg AK. Immediate loading of titanium hexed screw-type implants in the edentulous patient: case report. Implant Dent 2000; 9(4):351-6.

19. Becker W, Sennerby L, Bedrossian E, Becker BE, Lucchini JP. Implant stability measurements for implants placed at the time of extraction: A cohort, prospective clinical Trial. J Periodontol 2005; 76:391-7.

20. Groisman M, Frossard WM, Ferreira HM, Menezes Filho LM, Touati B. Single-tooth implants in the maxillary incisor region with immediate provisionalization: 2-year prospective study. Pract Proced Aesthet Dent 2003; 15:115-22.

21. De Kok IJ ${ }^{1}$, Chang SS, Moriarty JD, Cooper LF. A retrospective analysis of peri-implant tissue responses at immediate load/provisionalized microthreaded implants. Int Oral Maxillofac Implants 2006; 21(3):405-12.

22. Mesquita AMM, Neto JDP, Dávila P. Implantodontia Clínica baseada em evidência científica. In: Shibli J. Reabilitação protética utilizando implantes osseointegráveis: Planejamento 3D. São Paulo: Quintessence; 2012. p. 92-115.

Endereço para correspondência:

Catiélys Níobe Matiello

Rua Florianópolis, 100E. Apto 302 Centro

89812-120 Chapecó, SC

Telefone: 5481321185

E-mail: catielysm@hotmail.com

Recebido: 25/11/14. Aceito: 30/06/15. 